Finalmente, se abrió una rueda de preguntas, entre una de ellas planteadas en relación a la Provincia ¿En qué aspectos Tungurahua contribuye en el desarrollo y ejecución de la matriz productiva?, respondió que el porcentaje de contribución de Tungurahua al PIB Nacional es bajo, pero que se puede incrementar a través del desarrollo de cadenas productivas, que en esta zona geográfica se enfocaría en aspectos alimentarios y lácteos tecnificados con centros de acopio; serán necesarias reformas agrarias y la participación directa de la Academia a través de la Universidad Técnica de Ambato. Un ejemplo analizado fue la industrialización de la papa, mediante la generación de harina de papa que sustituya la importación de harina de trigo.

En conclusión, la transformación de la matriz productiva convertirá al país en generador y exportador de mayor valor agregado a través del aprovechamiento del conocimiento y el talento humano ecuatoriano, con inclusión de nuevos actores sobre la base de una adecuada redistribución y equidad, asegurando de esta manera el Buen Vivir para la población actual y la venidera.

\section{Referencias Bibliográficas}

- Secretaria Nacional de Planificación y Desarrollo, SENPLADES. Cambio de la Matriz Productiva.

- Ministerio Coordinador de Sectores Estratégicos, Sectores Estratégicos al cambio de la Matriz Productiva.

- http://www.planificacion.gob.ec/wp-content/uploads/ downloads/2013/01/matriz productiva WEBtodo.pdf

- $\quad$ http://www.ekosnegocios.com/revista/pdfTemas/736.pdf

Observatorio Económico y Social de Tungurahua (OBEST) Universidad Técnica de Ambato.

Ing. César A. Guerrero V.

\title{
EL DINERO ELECTRÓNICO
}

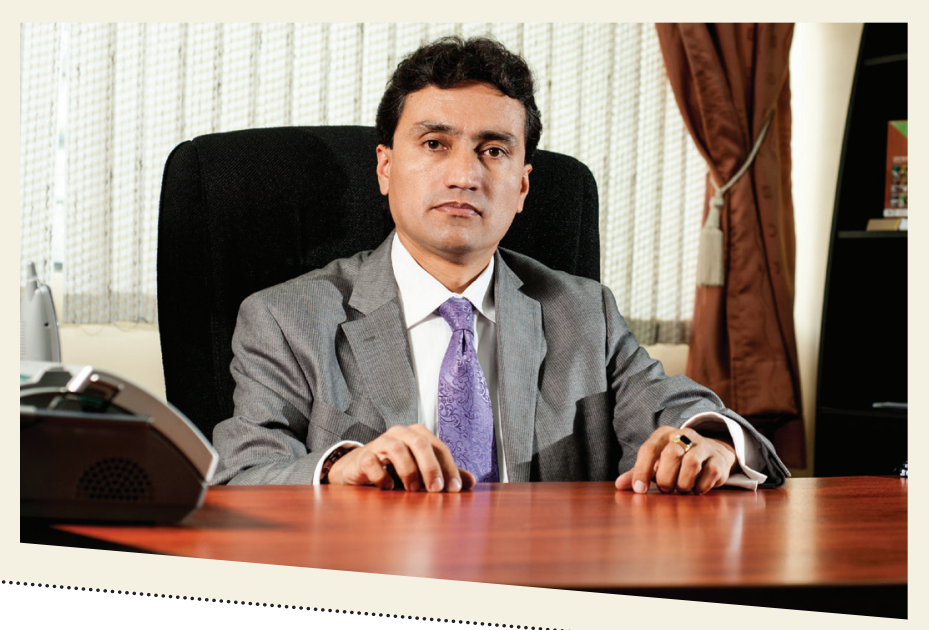

En países industrializados como Estados Unidos, Japón, Canadá, Inglaterra, Alemania, Francia e Italia entre otros, el pago de las transacciones de compra venta de bienes y servicios por pequeños o grandes que sean, se lo hace a través de una tarjeta de crédito, de débito o cheque, por ejemplo pagar el parqueo, la compra de una hamburguesa, de un pantalón, del combustible, sólo para citar algunos casos, facilitando la negociación en forma segura, ágil y exacta en tiempo real sin la necesidad de la presencia física del dinero; de hecho, casi el $80 \%$ de las transacciones en esos países se efectúan así porque en todo lugar prefieren ejecutar los pagos y cobros mediante estos mecanismos electrónicos, al contrario de nuestras economías tradicionalistas que no estamos seguros si no vemos y tenemos en nuestras manos las monedas y billetes. 
En este contexto y con el fin de proporcionar al ciudadano de cualquier estrato, el Banco Central del Ecuador, anunció mediante Resolución Administrativa 037-2014 del 28 de febrero de este año, la implementación del SDE (Sistema de Dinero Electrónico), también llamado billetera móvil o monedero electrónico y en regulación 055, del Título I denominado "Manual de Procedimiento y Operación del SDE" del 2 de junio, aclara algunos aspectos transaccionales, indicando que el único requisito para este mecanismo es el de poseer un teléfono celular y acceder a una clave y así se puede realizar pagos desde la comodidad y seguridad de la casa u oficina, permitiendo el cumplimiento oportuno del pago, la cancelación del valor exacto, sin recargos adicionales, evitando el deterioro físico del dinero por su manipulación y el $100 \%$ de seguridad porque al cargar en su celular una cantidad predefinida, puede hacer uso de esta para realizar compras de inmediato o si prefiere transferir a una cuenta personal para tener disponibilidad o liquidez propia, por tanto siendo un servicio público sin fines de lucro, se espera que no se incremente al valor de la transacción ninguno adicional que termine encareciendo el bien o servicio adquirido, tal como sucede hoy cuando se compra con tarjeta de crédito.

Este mecanismo se sustenta en varios factores: El primero El Consenso de Washington donde forman parte el Fondo Monetario Internacional, El Banco Mundial, Banco Interamericano de Desarrollo y la Organización Mundial del Comercio entre los más relevantes, en este se indica que "las medidas de gestión de los flujos de capital (CFMS) son herramientas de política macroeconómica para colaborar en la gestión del financiamiento sostenible de las economías" y por ello propone a sus signatarios aplicar políticas macroprudenciales que permitan a los gobiernos reducir el riesgo sistémico, evitar recetas dogmáticas como controlar el libre comercio a ultranza, y segundo en las leyes de Régimen Monetario y Banco del Estado y General de Instituciones del Sistema Financiero, se sustenta que para la emisión de dinero orgánico el Banco Central debe mantener en sus reservas en bóvedas un valor similar al que emitirá que puede ser en Oro Monetario, Divisas o en compensación de las exportaciones frente a las importaciones, cuentas que en conjunto se contabilizan como Reserva Internacional de Libre Disponibilidad RILD, sin embargo este sistema de Dinero Electrónico al no representar nueva emisión física de monedas y billetes y que por tanto no aumentará la masa monetaria (dinero y cuasidinero) en circulación, no requiere que el BCE construya una reserva extra por las transacciones que se den bajo este mecanismo. En la misma Regulación 055, el ex emisor aclara que " la entrega de dinero electrónico se realizará de manera directa o a través de agentes autorizados, únicamente contra similar canje de dólares (billetes o monedas) o depósitos en USD acreditados a favor del BCE", registrando de inmediato como un pasivo este depósito en sus balances, los cuales estarán respaldados al $100 \%$ con los activos de la RILD que hasta el 31 de mayo de 2014 alcanzó el valor de 3.568,9 millones de dólares, se espera que de tener aceptación el sistema de dinero electrónico, generaría unos 150 millones de dólares de movimiento diario, totalmente cubiertos con la Reserva Internacional.
La pregunta técnica y con sustento de la teoría económica es ¿Cuál es el respaldo monetario de este mecanismo?, la respuesta es que el mismo usuario de este servicio de pagos creará su reserva, porque cuando requiera hacer pagos, debe recargar en su celular un valor entregando dinero físico a algún agente autorizado (supermercado, banco, tienda, etc.) y estos a su vez trasferir a una cuenta en una entidad financiera privada, la cual de inmediato a través del sistema nacional de pagos llegan al Banco Central del Ecuador, quien a más de registrar como una obligación (pasivo), se reserva el uso de estos recursos, para el pago de la transacción que realice el beneficiario el momento que necesite disponer, convirtiéndose por tanto en una "Reserva Monetaria" que sustentará el pago que realizará, por ello no es indispensable crear una segunda reserva por parte del Banco Central, sin embargo y para mayor confiabilidad de los usuarios del dinero electrónico, pone a disposición la Reserva Internacional de libre Disponibilidad. Por cualquier parte el uso del dinero electrónico de los ciudadanos estará garantizado su retorno.

Otro aspecto que se podría analizar es aquel que sostienen algunos analistas, que este mecanismo podría provocar inflación en la economía ecuatoriana porque aumentaría la masa monetaria es decir el dinero y cuasidinero en circulación y que con ello también se incrementará la velocidad del dinero, por tanto al haber más dinero en la economía que circula más rápidamente, termina ejerciendo presión en la oferta y demanda de bienes y servicios que provoque una subida de precios en los mercados es decir inflación. Al respecto este escenario planteado es bastante difícil que se dé, porque no habrá aumento de la masa monetaria en virtud que el mismo dinero que actualmente está circulando seguirá haciéndolo, un ciudadano en lugar de pagar con efectivo, lo hará con dinero electrónico y el efectivo entregará al agente de pago el que a su vez depositará en el Banco Central, por tanto no generará un mayor volumen monetario en circulación, lo que podría suscitarse con el tiempo en mediano plazo podría ser siempre y cuando tenga una excelente aceptación el mecanismo es un aumento de la velocidad del dinero (físico o electrónico), para lo que oportunamente las autoridades de control, deberán tomar las medidas adecuadas para contrarrestar este posible escenario y enfriar la economía.

En resumen el uso del dinero electrónico debe implementarse ordenadamente con toda la información posible para los usuarios, procurando crear una cultura de su utilización y beneficios, adaptando sistemas informáticos confiables y prácticos, porque a decir verdad ésta es una herramienta necesaria que debemos adoptar los ecuatorianos, para caminar acorde a los avances de la tecnología moderna.

\author{
Econ. Mg. Diego Proaño \\ DECANO DE LA FACULTAD DE CONTABILIDAD Y AUDITORÍA
}

